Document downloaded from:

http://hdl.handle.net/10251/157575

This paper must be cited as:

Llopis Albert, C.; Rubio Montoya, FJ.; Valero Chuliá, FJ. (2019). Fuzzy-set qualitative comparative analysis applied to the design of a network flow of automated guided vehicles for improving business productivity. Journal of Business Research. 101:737-742. https://doi.org/10.1016/j.jbusres.2018.12.076

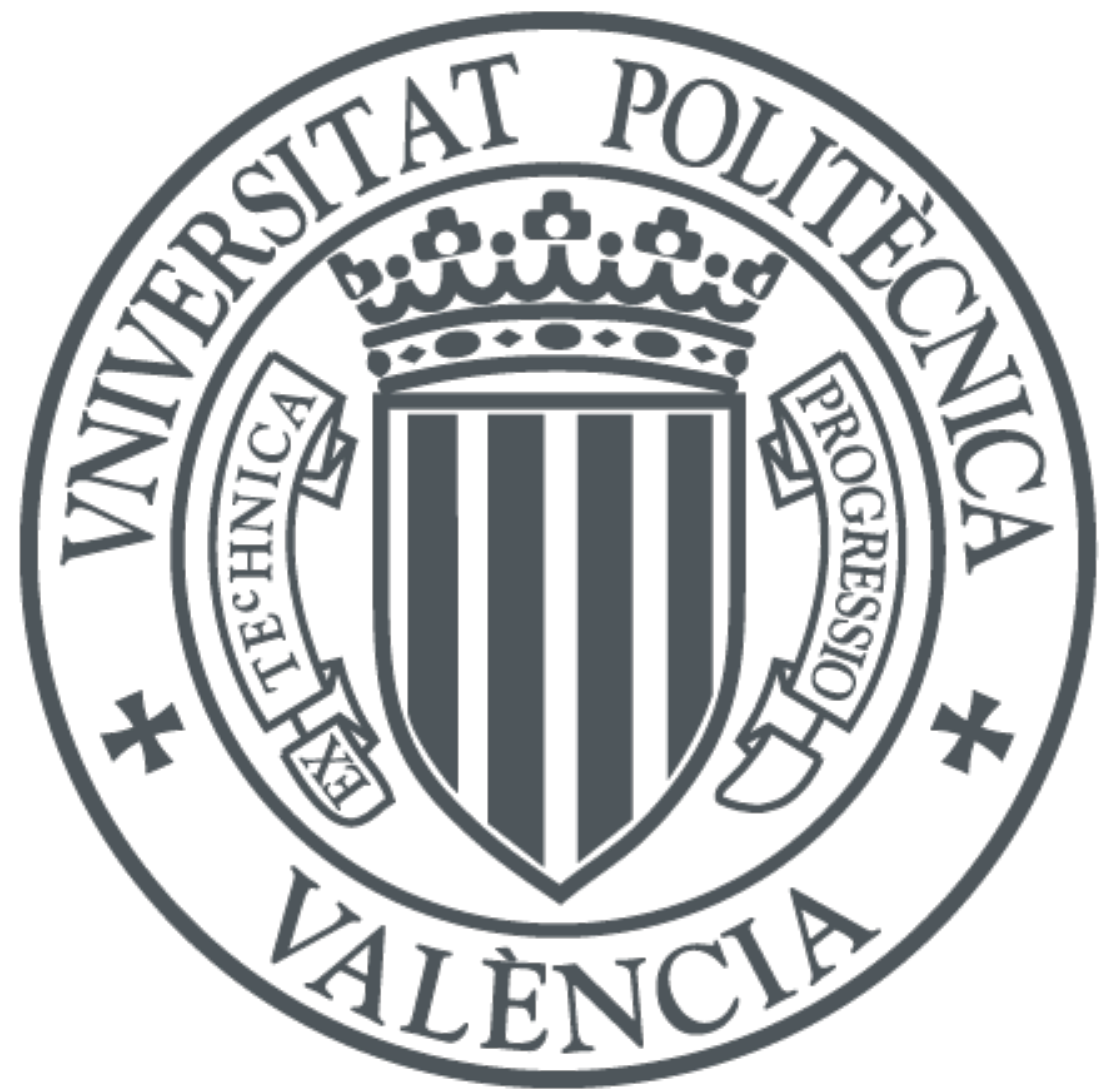

The final publication is available at

https://doi.org/10.1016/j.jbusres.2018.12.076

Copyright Elsevier

Additional Information 


\title{
Fuzzy-set qualitative comparative analysis applied to the design of a network flow of automated guided vehicles for improving business productivity
}

\author{
Carlos Llopis-Albert, Francisco Rubio, Francisco Valero \\ Centro de Investigación en Ingeniería Mecánica (CIIM), Universitat Politècnica de València, \\ Camino de Vera s/n, 46022, Valencia, Spain
}

\begin{abstract}
Designing efficient warehouse management systems is essential to improve business performance. The use of autonomous guided vehicles (AGVs) in logistic processes and material handling systems (MHS) improves productivity and reduces costs. However, determining the appropriateness and financial feasibility of acquiring a fleet of AGVs, together with the definition of their path layout, routing schemes, operation tasks, and network flow, becomes a complex problem when designing flexible manufacturing systems (FMS). This study aids the design of a fleet of AGVs by means of a fuzzy-set qualitative comparative analysis (fsQCA), which makes it possible to measure the level of satisfaction of managerial decision makers. It enables us to identify a combination of factors that lead to stakeholders' satisfaction while dealing with uncertain environments due to the heterogeneous nature of decision makers and factors. Our methodology has been applied to multi-criteria decision-making analysis, resulting in greater transparency, fairness, social equity, and consensus among stakeholders.
\end{abstract}

Keywords: fuzzy sets; qualitative comparative analysis; autonomous guided vehicles; conflict of interest; decision-making; material handling systems.

\section{Introduction.}


Material handling systems (MHS) and flexible manufacturing systems (FMS) play an important role in manufacturing performance (Sarker \& Gurav, 2005). An inadequate design may lead to considerable losses in productivity and competitiveness. MHS and FMS have improved significantly in recent years due to the use of automated guided vehicles (AGVs). AGVs are programmable driverless vehicles used to carry loads to different points in the facility in order to perform a certain task within a set time frame (Nakano \& Ohno, 1999). They encompass the vehicle, onboard controller, and the management, communication, and navigation system. AGVs can be considered as multiple systems that can operate independently as well as in cooperation with each other (Pillac et al., 2013). AGVs are attracting increasing attention and are rapidly being adopted in many industrial and service applications. They are extensively used in many transport applications and also for multi-tasking in other jobs related to service and manufacturing organizations. AGV systems also enable better adaptation to changes in market demands and make it possible to deal with uncertain environments. Furthermore, an efficient deployment of automated technologies in companies leads to enormous benefits (Jain et al., 2013). These benefits include an improvement in the system's efficiency, a decrease in operational and labor costs (even when compared to other transport systems such as belt conveyors), effective inventory control, greater safety and quality assurance, increased production, improvements in the use of space, flexible routing, and increased work precision. They also provide more flexible material handling due to the ease with which the AGV system can be redesigned to accommodate frequent changes, for instance, in product demand or in the workforce. Additionally, the use of AGV systems substantially decreases the number of work accidents due to transport and warehouse activities in comparison with human operations (e.g. Gnanavel-Babu et al., 2010). This is of particular importance nowadays, when occupational health and safety plays such a major role. Another important feature when designing a network flow is that it must avoid collisions and minimize transportation times. 
This will enhance performance, since more tasks can be handled within a certain time (Fazlollahtabar et al., 2015).

An AGV network flow consists of open aisles between machines, allocation of stacking areas, workstations, departments and fixed structures on the facility layout. Normally, AGVs navigate along predefined guided paths. Guidance technologies include physical guide paths such as track-buried cables or guide paths painted on the floor, optical sensors, laser navigation systems based on fixed reflectors located in the workplace, magnet- and gyroscope-based inertial guidance and wireless technologies. The last of these guidance techniques provides some advantages, since it is not necessary to cut or paint the floor and the guide paths can be easily modified. Additionally, there are different systems to connect a pair of nodes in the network such as unidirectional, bidirectional, multi-lane, and mixed systems. There may also be two-way lanes in the same aisle for heavy traffic conditions. A wide range of algorithms are provided in the literature to deal with routing and scheduling problems for AGVs (Biçer \& Seifert, 2017). Two broad categories can be distinguished: static and dynamic approaches. In the first approach the route is determined in advance, which means that the algorithms are unable to adapt to changes in the logistic system and traffic conditions. In the second approach the route is based on real-time information, which allows different routes between locations to be dynamically determined. This helps solve problems due to changes, thus providing FMS and scalable MHS (Gourgand et al., 1995). The problem of AGV system routing is continually being developed. Several works have presented the state-of-the-art on this subject (e.g. Bodin et al., 1983; Psaraftis 1988, 1995; Laporte 1992; Fisher, 1995; Pillac et al., 2013; Kelly \& Xu, 1999; and Fazlollahtabar et al., 2015).

This paper addresses the design of an efficient AGV fleet taking advantage of fuzzy-set qualitative comparative analysis (fsQCA) (Ragin, 2008). The multi-criteria decision-making (MCDM) analysis will be tackled considering a wide range of factors (including management, 
financial, and technical factors), as explained in the next section. The findings of this paper provide insight into which configuration of factors leads to the outcome (i.e. stakeholders' satisfaction).

\section{Method.}

\subsection{Design of an efficient AGV system.}

The main objectives in designing an efficient AGV system entail a wide range of considerations, including management, financial, and technical factors. The usefulness of considering such a variety of factors to improve assembly line productivity has already been discussed in the literature (e.g. Llopis-Albert et al., 2015; 2016). The management and financial factors include assessing the feasibility of AGV systems, investment costs (acquisition and installation), payback periods, transportation, operational, energy and maintenance costs, cost of possible dismissals of workers due to process automation and subsequent conflicts with labor unions, training for non-qualified workers, equipment costs (such as guide path wires and communication links), costs of computers and software for controlling the network flow, annual savings, improvements in productivity and performance, and adaptability to changes (e.g. to address possible fluctuations in demand and failures in the production line or AGV system, machine restrictions, number of workers, number of shifts, need to manufacture different products, etc.).

The technical factors relate to the best choice regarding the type of AGV system to use, which can be categorized as towing vehicles, unit-load carriers, pallet trucks, fork trucks, and assembly lines. They also include the kind of guidance technologies used, which comprise physical guide paths (colored and magnetic lines), optical sensors, laser navigation systems, magnet- and gyroscope-based inertial guidance, and wireless technologies. An efficient design of AGV systems should also take into account problems such as path layout and route schemes and how they affect the facility layout. Then different movements of the AGV can be designed, 
for instance, U-turns, curves or sharp turns, or free-ranging movements. The design process involves achieving minimum travel times, maximum vehicle utilization (i.e. maximum load capacity per vehicle, reduction of empty vehicle travel and idle points), minimum time for loading and battery-charging, minimum queue length, minimum inventory level, estimation of the number of vehicles (i.e. fleet size) needed to meet the transportation demands according to the manufacturing system planning, determination of loading times, vehicle maneuverability (i.e. steering angles and axes, the vehicle's degrees of freedom, number of motors, acceleration, and rotation), traffic control schemes, optimal allocation of stacking areas, maximization of space utilization, traffic and battery management, number and location of load/unload points, and the design of the complete network flow. Other technical considerations relate to safety, standardization of the workflow, vehicle scheduling/dispatching of operation tasks, energy consumed, ergonomic and ecological considerations, level of computerization for controlling the network flow, and the complexity of its use. Furthermore, the design of the AGV fleet should take into account possible fluctuations in demand and failures in the production line or the AGV system, machine restrictions, number of workers, and number of shifts in order to achieve flexible manufacturing systems (FMS).

\subsection{Overview of fuzzy-set qualitative comparative analysis.}

The fsQCA is a configurational comparative method based on set theory and fuzzy logic (Ragin, 2008). An exhaustive explanation of the theoretical aspects of fsQCA can be found in Mendel and Korjani $(2012,2013)$. This technique has been applied to complex qualitative comparative problems in many research areas (e.g. Berbegal-Mirabent \& Llopis-Albert, 2015; Hasselström \& Hakansson, 2014; Knieper \& Pahl-Wostl, 2016; Llopis-Albert \& Palacios-Marqués, 2016; LlopisAlbert, et al., 2017; Zhou et al., 2015). 
The ultimate goal of the methodology is to determine which combination of factors (i.e. a configuration or pathway) is minimally necessary and/or sufficient to achieve a specific outcome and to identify which groups of cases share a certain combination of conditions (Meyer et al., 1993). A configuration is made up of conditions or factors that can be positive, negative or absent. On the one hand, a condition is necessary if a specific outcome cannot be achieved without it. On the other hand, a condition is sufficient if it leads to the outcome by itself without the help of other conditions (Ragin, 2008). The methodology presupposes complex causality and asymmetric relationships that reveal configurations that are sufficient to lead to a specific outcome. There are conditions that are sufficient or necessary for all cases studied. However, conditions may be sufficient and necessary when combined with other conditions (i.e. conjunctural causation) or may represent only one alternative among others, which is applicable to some cases but not to others (i.e. equifinal causation). The methodology therefore assumes that many pathways may lead to the same outcome.

The limitation of dealing only with binary variables can be overcome with fsQCA. Indeed, it allows us to analyze varying levels of belongingness of cases to a particular set. To do that, the outcome and causal conditions are defined as fuzzy sets, where membership functions (MFs) must be established. The first step is to perform a calibration procedure in which the data are converted into measures of set membership through theoretical or substantial knowledge external to the empirical data, thus categorizing meaningful groupings of cases (Ragin, 2008). Fuzzy values (i.e. the degrees of membership in a certain set) range from full membership (1) to non-membership (0), while the crossover point (0.5) represents neither in nor out of the set. The second step is to construct a truth table, a matrix with $2^{k}$ rows where $k$ is the number of causal conditions (configuration) and each column represents an antecedent condition (factor). The number 2 is chosen because it is considered both the causal condition and its complement. The truth table depicts all logically possible combinations of causal conditions 
and classifies the cases according to the logically possible combinations. Each empirical case matches a certain configuration, in accordance with which antecedent conditions the case meets (Fiss, 2011).

The third step is to reduce the number of rows in the truth table. This step is commonly carried out by means of the Quine-McCluskey algorithm (Quine, 1952). It uses Boolean algebra to obtain a set of combinations of causal conditions, where each combination is minimally sufficient to produce the outcome. This process is based on several indicators, such as the consistency and the coverage (Ragin, 2008). The consistency quantifies the degree to which instances sharing similar conditions display the same outcome (Ragin, 2008). Therefore, it measures the degree to which membership in the solution (the set of solution terms) is a subset of membership in the outcome. The coverage shows the empirical relevance of a solution, and hence, it measures the proportion of memberships in the outcome explained by the complete solution. The raw coverage expresses the share of the outcome that is explained by a specific configuration (i.e. solution). The unique coverage illustrates the share of the outcome that is exclusively explained by a specific configuration.

\section{Application to a case study.}

The fsQCA technique is applied to provide insight into the design project of a network flow of AGVs for efficient MHS. It has the advantage of dealing with uncertain environments due to the heterogeneous nature of the stakeholders involved and the different factors leading to their satisfaction. This approach also allows us to consider the actors' level of participation and their degree of influence on the decision-making process in designing the AGV system. The outcome of the multi-criteria decision-making problem is the actors' satisfaction. The actors considered in this study include shareholders, managers, labor unions, and workers. The criterion used to choose the actors is based on considering all groups who will be affected in 
some way by the implementation of the AGV system. This includes those who have some interest in the benefits of its implementation and those who are likely to suffer the consequences. This study covers small and medium-sized enterprises (SMEs) but also large companies from different industrial sectors in the Valencian Community (Spain), based on regional government reports, public domain information, meetings, personal interviews, surveys, mass media information, and expert opinions. In this way, three levels of participation are considered, namely information (actors are only informed), consultation (actors express their opinions, which are taken into account in the decision-making process), and active involvement (actors are engaged in the search for solutions and have the authority to codecide). Of course, the level of participation and degree of influence is different for each type of business entity (which includes corporations, cooperatives, partnerships, sole traders, limited liability companies, and others), size of company (SMEs and large or multinational companies), and legal system in different countries. In this regard, this methodology can be adapted to different realities.

On the one hand, the active involvement of all actors in management decisions has positive effects on business performance, providing greater transparency, fairness, social equity, and consensus among actors. This is because it produces synergies between them on account of their different values, levels of knowledge, resources, interests, and perceptions regarding the problem and possible solutions and strategies to be undertaken. In addition, the actors' engagement also brings together different points of view, leads to better use of information and management, increases the legitimacy of final decisions, reinforces democratic practices, and increases workers' confidence in their managers. On the other hand, the heterogeneity of the actors leads to a conflict of interests, which complicates the problem.

Table 1 shows the factors or conditions used in fsQCA that may lead to the actors' satisfaction when designing AGV systems. 
Table 1 here.

The actors' degree of preference or acceptance with regard to the different factors is analyzed using a continuous fuzzy set. The values range from 0 (i.e. low degree of acceptance or agreement) to 1 (i.e. high degree of acceptance or agreement). Thirteen factors are considered, which encompass several subfactors (Table 2). The calibration process is carried out to transform the actors' preferences regarding the antecedent conditions into fuzzy variables in such a way that they match or conform to external standards. One advantage of fuzzy sets is that they can deal with both quantitative and qualitative measurements, and hence, they overcome some of the limitations of both. Furthermore, fuzzy sets enable appropriate treatment of multiple data sources, as is the problem when designing AGV systems.

The calibration is based on the available information, which is organized using variables on a Likert scale or interval scale. These psychometric scales are extensively used for scaling information. They are representations of numerical values, such as the budget each actor is willing to devote to a certain measure. An underlying concept, such as investment in acquiring the AGV system, can therefore be structured and labeled in set theoretic terms; for instance, "degree of membership in the set of willing to invest more than a certain quantity", which could be based on the company's turnover. Therefore, the actor's degree of agreement regarding a certain statement could be categorized using a five-level Likert scale, for example: "strongly disagree", "disagree", "neither agree nor disagree", "agree", and "strongly agree". The conversion between these verbal labels and fuzzy scores is carried out by means of 3 qualitative anchors that structure fuzzy sets. Therefore, 1.0 and 0.0 are the threshold for full membership and non-membership of a certain set, respectively, while 0.5 is the crossover point dividing "more in" from "more out" with regard to a specific statement. This represents the actors' maximum ambiguity regarding their membership in the set. 
During the calibration process the fuzzy scores must also take into account the actors' level of participation (information only, consultation, or active involvement), the degree of influence on the final decisions to be implemented, and the different industrial sectors and financial situation of the companies. In addition, this study uses the size (number of employees) and turnover of the company to homogenize the results, i.e. these values are used to make results comparable across different companies and realities. Obviously, shareholders and management have more influence than labor unions or workers. Therefore, appropriate fuzzyset membership scores are assigned to actors with more influence and a greater level of participation. Actors with a greater influence and level of participation are therefore considered to be more difficult to satisfy.

The aggregate final score for each condition is obtained by means of the arithmetic average of the fuzzy scores for each subfactor. As a summary, during the calibration of fuzzy sets, the verbal labels of the scales should be converted into metrics without any loss of information, thus making it possible to scale the degree of membership while taking into account qualitative differences between actors and conditions. After the calibration process, the truth table obtained after several rounds of analyses is analyzed by means of fsQCA software (Ragin, 2008).

Since there are thirteen factors, the matrix dimensions are $\left(2^{13}\right)$ rows (i.e. 8192 possible configurations) and 13 columns. It is first tested for necessary conditions for the outcome and also for the negation of those conditions, indicated by the tilde ( ) sign in Table 2.

Table 2 here.

A condition is considered necessary when its consistency score exceeds the threshold value of 0.9 (Schneider et al., 2010). Table 2 shows the consistency and coverage values for all factors. These values show that only two out of thirteen factors show a consistency above the 
threshold. Specifically, these two factors are C2 (improvement of productivity and performance) and C4 (achievement of flexible manufacturing systems). They are the necessary conditions leading to the outcome. Therefore, these factors need to be present in order to achieve stakeholder satisfaction. The results also show that, aside from the necessary conditions, there are other factors that appear in most of the configurations, for instance, the annual savings. This proves that actors' satisfaction depends on a wide range of factors because of the high heterogeneity of actors with conflicting interests.

The truth table is minimized using Boolean algebra. It returns a set of combinations of causal conditions, where each combination is minimally sufficient to lead to the outcome. The minimization process is carried out using the coverage and consistency values.

Table 3 presents the 13 solutions that are found by the algorithm. In accordance with Ragin's (2009) recommendation, this work presents the intermediate solution. In addition, following the notation presented by Ragin and Fiss $(2008)$, black circles $(0)$ indicate the presence of a factor, white circles $(O)$ represent its absence, and blank cells denote ambiguous factors. The diversity of these configurations suggests that they are sufficient but not necessary. Therefore, no unifying configuration explains the actors' satisfaction. In addition, all configurations show acceptable consistency values $(<0.80)$. Furthermore, high raw coverage values are attained.

Table 3 here.

Some of the stakeholders may lack appropriate knowledge about certain management, financial, and technical issues. Hence, during the different rounds of fsQCA the results can be presented to stakeholders. This is because the results are easily understandable for nonexperts in those issues. In addition, the key management, financial, and technical concepts can be explained to stakeholders during the different rounds to attain results with more consensus. Furthermore, with this approach stakeholders will achieve a deeper understanding 
of the design and implementation of AGV systems (Mandell, 2001). Note that different mechanisms can be used to engage actors, such as meetings, workshops, conferences, expert panels, web-based communication technologies, consultation of industry associations and labor unions, and surveys.

Uncertainty in fsQCA can also be taken into account in order to enhance the level of confidence in the results. In this regard, the reliability and validity of the results is assessed by means of robust tests. They are based on some parameters of fit such as consistency, raw coverage, and unique coverage. Tables 2 and 3 present the results of those tests, showing satisfactory levels of confidence in the different solution terms as established by Ragin (2008).

With regard to the non-necessary conditions, the results are imprecise. In spite of the presence of those conditions in several configurations, their absence is relevant in other recipes. It is worth mentioning that the presence or absence of those conditions in a certain configuration is due to the actors' heterogeneity.

As a rule of thumb, to obtain good outcomes stakeholders must be engaged at early stages and should be provided with clear goals, information, and organization (e.g. a suitable agenda and mechanisms to engage actors, and appropriate steps for the whole process). This is because they are less likely to hinder decisions and more likely to support them. Moreover, satisfied actors are less prone to delay the decision-making process by means of their opposition, for example, by litigation (Berry et al., 1993).

\section{Conclusions}

Today's rapid technological developments offer manufacturing firms a variety of alternatives for in-plant transportation. A common solution to this problem is the use of AGV systems. A powerful technique, based on fsQCA, has been successfully applied to a real case study with 
the aim of aiding the decision-making process during the design and implementation of a network flow of AGV systems. Results have shown that stakeholders pay more attention to management and financial factors than to technical ones. This is true no matter which technical conditions are used to achieve the financial goals. However, shareholders and managers focus more on obtaining profits, while labor unions and workers have a greater interest in maintaining the current jobs and are concerned about technical factors such as handling difficulties and safety. Therefore, the only necessary conditions (i.e. those which all actors agree must be present in order to achieve their satisfaction) are improvements in productivity and performance and the achievement of flexible manufacturing systems. This is because these conditions presumably favor all actors.

Actively involving stakeholders with conflicting interests in management decisions has positive effects on business performance, while providing higher levels of transparency, fairness, social equity, and consensus among them. In addition, the methodology leads to a greater understanding of the problem for all stakeholders and reduces the possibility of delays in implementing the measures due to labor union strikes or litigations. Furthermore, the use of AGVs for efficient warehousing also increases flexible manufacturing systems, since the network flow can be easily reconfigured to accommodate production changes. This approach can also be easily adjusted to each company's specific case (e.g. size and level of turnover), the type of products manufactured, and transportation tasks for warehousing. In addition, the design of AGV systems must deal with uncertainty due to imperfect and/or unknown information, and scarce or inappropriate actor participation. In this regard, the methodology helps companies remain competitive under conditions of uncertainty in the market. Therefore, fsQCA can be used as a system to support decision-making processes in uncertain environments in order to achieve FMS. 


\section{References}

Berbegal-Mirabent, J. \& Llopis-Albert, C. (2015). Applications of Fuzzy Logic for Determining the Driving Forces in Collaborative Research Contracts. J. Bus. Res., 69 (4), 1446-1451. DOI: 10.1016/j.jbusres.2015.10.123.

Biçer, I. \& Seifert, R. W., (2017). Optimal Dynamic Order Scheduling under Capacity Constraints Given Demand-Forecast Evolution. Production and Operations Management 26(12), 22662286. DOI: $10.1111 /$ poms.12759.

Bodin, L. D. (1983). Routing and scheduling of vehicles and crews: The state of the art. Computers and Operations Research 10(2), 63-211.

Fazlollahtabar, H. \& Saidi-Mehrabad, M. (2015). Autonomous Guided Vehicles: Methods and Models for Optimal Path Planning. Springer. DOI: 10.1007/978-3-319-14747-5. ISBN 978-3319-14747-5.

Fazlollahtabar, H. \& Mahdavi-Amiri, N. (2013). Producer's behavior analysis in an uncertain bicriteria AGV-based flexible jobshop manufacturing systems with expert system. International Journal of manufacturing Technology, 65, 1605-1618.

Fisher, M. (1995). Vehicle routing. In: Ball, M.O., Magnanti, C.L., Monma, C.L., \& Nemhauser, G.L. (eds.) Network Routing, pp. 1-33. Elsevier, Amsterdam.

Fiss, P. C. (2011) Building Better Causal Theories: A Fuzzy Set Approach to Typologies in Organization Research. Acad. Manage. J., 54 (2), 393-420.

Gnanavel-Babu, A., Jerald, J., Noorul, A., Muthu, V., \& Vigneswaralu, T.P. (2010). Scheduling of machines and automated guided vehicles in FMS using differential evolution. International Journal of Production Research 48:16, 4683-4699.

Gourgand, M., Sun, X. C., \& Tchernev, N., (1995). Choice of the guide path layout for an AGV based material handling system. Emerging Technologies and Factory Automation, 1995. ETFA '95, Proceedings., 1995 INRIA/IEEE Symposium on. DOI: 10.1109/ETFA.1995.496688.

Hasselström, L. \& Hakansson, C. (2014) Detailed Vs. Fuzzy Information in Non-Market Valuation Studies: The Role of Familiarity. J. Environ. Plann. Manage., 57 (1).

Jain, A., Jain, P. K., Chan, F. T. S., \& Singh, S. (2013). A review on manufacturing flexibility. International Journal of Production Research 51(9), 5946-5970.

Kelly, J. P. \& Xu, J. (1999). A set-partitioning-based heuristic for the vehicle routing problem. Journal on Computing 11(2), 161-172.

Knieper, C. \& Pahl-Wostl, C. (2016) A Comparative Analysis of Water Governance, Water Management, and Environmental Performance in River Basins. Water Resources Management, 30 (7), 2161-2177.

Laporte, G. (1992). The vehicle routing problem: An overview of exact and approximate algorithms. European Journal of Operational Research 59(3), 345-358. 
Llopis-Albert, C., Rubio, F., \& Valero, F. (2015). Improving productivity using a multi-objective optimization of robotic trajectory planning. Journal of Business Research 68, 1429-1431. DOI: 10.1016/j.jbusres.2015.01.027.

Llopis-Albert, C. \& Palacios-Marqués, D. (2016). Applied Mathematical Problems in Engineering. Multidisciplinary Journal for Education, Social and Technological Sciences 3(2), 114. DOI: $10.4995 /$ muse.2016.6679.

Llopis-Albert, C., Rubio, F., \& Valero, F. (2018). Optimization approaches for robot trajectory planning. Multidisciplinary Journal for Education, Social and Technological Sciences 5(1), 1-16. DOI: 10.4995/muse.2018.9867.

Llopis-Albert, C., Merigó, J. M., Xu, Y., \& Liao, H. (2017). Application of Fuzzy Set/Qualitative Comparative Analysis to Public Participation Projects in Support of the EU Water Framework Directive. Water Environment Research, 89. Doi:10.2175/WERD1600372.

Mendel, J. M. \& Korjani, M. M. (2012). Charles Ragin's Fuzzy Set Qualitative Comparative Analysis (fsQCA) Used for Linguistic Summarizations. Inf. Sci., 202, 1-23.

Mendel, J. M. \& Korjani, M. M. (2013). Theoretical Aspects of Fuzzy Set Qualitative Comparative Analysis (fsQCA). Inf. Sci., 237, 137-161.

Meyer, A. D., Tsui, A. S., \& Hinings, C. R. (1993). Configurational approaches to organizational analysis. Academy of Management Journal, 36(6), 1175-1195.

Nakano, M. \& Ohno, K. (1999). Decomposition algorithm for performance evaluation of AGV systems. Production and Operations Management 8(2), 193-205. DOI: 10.1111/j.19375956.1999.tb00370.x.

Quine, W. V. (1952). The problem of simplifying truth functions. The American Mathematical Monthly, 59(8), 521-531.

Pillac, V., Gendreau, M., Guéret, C., \& Medaglia, A. L. (2013). A review of dynamic vehicle routing problems. European Journal of Operational Research 225, 1-11. DOI: 10.1016/j.ejor.2012.08.015.

Psaraftis, H. (1988). Dynamic vehicle routing problems. In Golden, B. and Assas, A., editors, Vehicle Routing: Methods and Studies, 223-248. Elsevier Science Publishers B.V.

Psaraftis, H. N. (1995). Dynamic vehicle routing: Status and prospects. Annals of Operations Research 61(1), 143-164.

Ragin, C. C. (2008). Redesigning social inquiry: Fuzzy sets and beyond. Chicago: University of Chicago Press.

Sarker, B. R. \& Gurav, S. S. (2005). Route planning for automated guided vehicles in a manufacturing facility. International Journal of Production Research 43(21), 4659-4683.

Zhang, M., Batta, R., \& Nagi, R. (2008). Modeling of workflow congestion and optimization of flow routing in a manufacturing/warehouse facility. Management Science 55, 267-280.

Zhou, Y., Huang, G., Wang, S., Li, Z., \& Zhou, Y. (2015) Factorial Fuzzy Programming for Planning Water Resources Management Systems. J. Environ. Plann. Manage. DOI: 10.1080/09640568.2015.1093924. 
Table 1. Factors or conditions considered in fsQCA. Considerations used to design AGV systems, including management, financial, and technical issues.

\begin{tabular}{|c|c|}
\hline \multicolumn{2}{|r|}{ Factors or antecedent conditions (C) } \\
\hline \multirow{6}{*}{$\begin{array}{l}\text { Management } \\
\text { \& Financial }\end{array}$} & $\begin{array}{l}\text { C1: Feasibility of implementing the AGV system: } \\
\text { - Investment costs (acquisition and installation). } \\
\text { - Short implementation time. }\end{array}$ \\
\hline & C2: Improved productivity and maximization of performance. \\
\hline & C3: Annual savings. \\
\hline & $\begin{array}{l}\text { C4: Adaptability to changes in order to achieve FMS (e.g. to address possible } \\
\text { fluctuations in demand and failures in the production line or the AGV } \\
\text { system, restriction of machines, number of workers, number of shifts, need } \\
\text { to manufacture different products, etc.). }\end{array}$ \\
\hline & $\begin{array}{l}\text { C5: Other costs such as payback periods, transportation, operation, energy } \\
\text { and maintenance costs, depreciation, workers' dismissals and training, } \\
\text { equipment and software controlling costs. }\end{array}$ \\
\hline & C6: Implementation will not lead to layoffs. \\
\hline \multirow{7}{*}{ Technical } & $\begin{array}{l}\text { C7: Type of AGV system (i.e. towing vehicles, unit-load carriers, pallet trucks, } \\
\text { fork trucks, and assembly lines). }\end{array}$ \\
\hline & $\begin{array}{l}\text { C8: Minimum travel times: } \\
\text { - Definition of the optimal path layout, route scheme, and facility layout. } \\
\text { - Optimal allocation of stacking areas, maximizing the utilization of space, } \\
\text { number and location of load/unload points. }\end{array}$ \\
\hline & $\begin{array}{l}\text { C9: Optimal number of AGVs (fleet size) to satisfy the demand: } \\
\text { - Maximum vehicle utilization (i.e. maximum load capacity per vehicle, } \\
\text { reduction of empty vehicle travel and idle points). } \\
\text { - Minimum inventory level. }\end{array}$ \\
\hline & $\begin{array}{l}\text { C10: Optimal network flow: } \\
\text { - Efficient driverless traffic control schemes. } \\
\text { - Efficient rerouting in real time for collision avoidance. } \\
\text { - Minimum time for loading/unloading and battery-charging. } \\
\text { - Minimum queue length, minimum loading times, and reduction of idle } \\
\text { points. } \\
\text { - Standardization of the workflow. } \\
\text { - Efficient vehicle scheduling/dispatching of operation tasks. } \\
\text { - Level of computerization for controlling the network flow and the } \\
\text { complexity of its use. }\end{array}$ \\
\hline & $\begin{array}{l}\text { C11: Guidance technologies: } \\
\text { - Colored and magnetic lines, optical sensors, laser navigation systems, } \\
\text { magnet- and gyroscope-based inertial guidance, and wireless technologies. }\end{array}$ \\
\hline & $\begin{array}{l}\text { C12: Vehicle maneuverability: } \\
\text { - Steering angles and axes, the vehicle's degrees of freedom, number of } \\
\text { motors, acceleration, and rotation. } \\
\text { - Vehicle trajectories (i.e. U-turns, curves or sharp turns, or free-ranging } \\
\text { movements). }\end{array}$ \\
\hline & $\begin{array}{l}\text { C13: Other technical considerations such as safety, ease of use, energy } \\
\text { consumption, ergonomic and ecological considerations. }\end{array}$ \\
\hline Outcome & Actors' satisfaction \\
\hline
\end{tabular}


Table 2. Analysis of necessary conditions

\begin{tabular}{|c|c|c|}
\hline Conditions tested* & Consistency & Coverage \\
\hline Feasibility \& Investment costs & 0.818688 & 0.718891 \\
\hline$\sim$ Feasibility \& Investment costs & 0.522186 & 0.908204 \\
\hline Productivity \& Performance & 0.904768 & 0.708686 \\
\hline$\sim$ Productivity \& Performance & 0.495829 & 0.857526 \\
\hline Annual savings & 0.813995 & 0.835048 \\
\hline Annual savings & 0.570353 & 0.771792 \\
\hline Adaptability & 0.904192 & 0.786975 \\
\hline$\sim$ Adaptability & 0.415285 & 0.735227 \\
\hline Other costs (e.g. energy and maintenance) & 0.710327 & 0.694638 \\
\hline Other costs (e.g. energy and maintenance) & 0.622680 & 0.900870 \\
\hline No layoffs & 0.643229 & 0.803151 \\
\hline$\sim$ No layoffs & 0.626162 & 0.685901 \\
\hline Type of AGV system & 0.716289 & 0.684688 \\
\hline Type of AGV system & 0.487192 & 0.729732 \\
\hline Minimum travel times & 0.624372 & 0.734157 \\
\hline$\sim$ Minimum travel times & 0.743806 & 0.861560 \\
\hline Optimal fleet size & 0.554090 & 0.726872 \\
\hline Optimal fleet size & 0.797106 & 0.837744 \\
\hline Optimal network flow & 0.837439 & 0.843767 \\
\hline Optimal network flow & 0.520600 & 0.721766 \\
\hline AGV guidance technologies & 0.712802 & 0.734233 \\
\hline AGV guidance technologies & 0.630611 & 0.848766 \\
\hline Vehicle maneuverability & 0.663432 & 0.765997 \\
\hline$\sim$ Vehicle maneuverability & 0.721433 & 0.851066 \\
\hline Other technical considerations (e.g. safety and ease of use) & 0.707619 & 0.744357 \\
\hline Other technical considerations (e.g. safety and ease of use) & 0.643299 & 0.842963 \\
\hline
\end{tabular}


Table 3. Sufficient configurations of antecedent conditions for actors' satisfaction.

\begin{tabular}{|c|c|c|c|c|c|c|c|c|c|c|c|c|c|c|c|c|}
\hline \multirow{2}{*}{$\begin{array}{l}\text { Configurations } \\
\text { (C) }\end{array}$} & \multicolumn{13}{|c|}{ Antecedent conditions (factors) } & \multicolumn{2}{|c|}{ Coverage } & \multirow{2}{*}{ Consistency } \\
\hline & 1 & 2 & 3 & 4 & 5 & 6 & 7 & 8 & 9 & 10 & 11 & 12 & 13 & Raw & Unique & \\
\hline $\mathrm{C} 1$ & 0 & $\bullet$ & & 0 & 0 & $\bullet$ & $\bullet$ & $\bullet$ & 0 & 0 & 0 & & $\bullet$ & 0.399393 & 0.006967 & 0.934743 \\
\hline $\mathrm{C} 2$ & $\bullet$ & $\bullet$ & ○ & & & $\bullet$ & $\bullet$ & $\bullet$ & O & $\bullet$ & $\bullet$ & 0 & $\bullet$ & 0.446885 & 0.009705 & 0.998509 \\
\hline C3 & $\bullet$ & $\bullet$ & $\bullet$ & $\bullet$ & $\mathrm{O}$ & 0 & 0 & & 0 & 0 & 0 & 0 & 0 & 0.296996 & 0.020048 & 1.000000 \\
\hline C4 & $\bullet$ & $\bullet$ & $\bullet$ & $\bullet$ & 0 & 0 & O & 0 & & 0 & O & 0 & 0 & 0.319171 & 0.013411 & 0.998957 \\
\hline C5 & $\bullet$ & $\bullet$ & $\bullet$ & & 0 & 0 & 0 & 0 & $\bullet$ & $\bullet$ & 0 & 0 & 0 & 0.297467 & 0.000962 & 1.000000 \\
\hline C6 & $\bullet$ & $\bullet$ & $\bullet$ & $\bullet$ & $\bullet$ & 0 & 0 & 0 & $\bullet$ & 0 & & 0 & 0 & 0.361499 & 0.049536 & 1.000000 \\
\hline $\mathrm{C7}$ & $\bullet$ & $\bullet$ & $\bullet$ & $\bullet$ & $\bullet$ & 0 & 0 & & $\bullet$ & $\bullet$ & 0 & 0 & 0 & 0.303563 & 0.007653 & 1.000000 \\
\hline $\mathrm{C} 8$ & $\bullet$ & $\bullet$ & - & & - & - & - & & 0 & - & - & 0 & $\bullet$ & 0.395964 & 0.001963 & 1.000000 \\
\hline $\mathrm{C9}$ & 0 & $\bullet$ & $\bullet$ & $\bullet$ & & $\bullet$ & $\bullet$ & $\bullet$ & 0 & $\bullet$ & $\bullet$ & $\bullet$ & $\bullet$ & 0.368814 & 0.000110 & 0.943961 \\
\hline C10 & 0 & 0 & 0 & & 0 & $\bullet$ & $\bullet$ & 0 & 0 & 0 & 0 & $\bullet$ & 0 & 0.295386 & 0.015790 & 0.988313 \\
\hline C11 & 0 & $\bullet$ & 0 & & 0 & $\bullet$ & $\bullet$ & 0 & $\bullet$ & 0 & 0 & $\bullet$ & $\bullet$ & 0.309983 & 0.025813 & 0.990662 \\
\hline C12 & $\bullet$ & 0 & 0 & $\bullet$ & 0 & $\bullet$ & $\bullet$ & 0 & 0 & - & 0 & $\bullet$ & $\bullet$ & 0.367020 & 0.001607 & 1.000000 \\
\hline C13 & $\bullet$ & $\bullet$ & 0 & 0 & 0 & $\bullet$ & $\bullet$ & 0 & 0 & $\bullet$ & 0 & 0 & $\bullet$ & 0.377512 & 0.000451 & 0.999972 \\
\hline
\end{tabular}

Note: 1. Black circles $(\bullet)$ indicate the presence of a condition, white circles $(O)$ denote its absence, and blank cells represent ambiguous conditions. 2. Frequency threshold $=1$; consistency threshold $=0.950909$. 